\title{
Poor ventilatory reponse to mild hypoxia may inhibit acclimatization at moderate altitude in elderly patients after carotid surgery
}

\author{
G. Roeggla, M. Roeggla, A. Wagner and A. N. Laggner \\ Department of Emergency Medicine, University of Vienna, Austria
}

\begin{abstract}
Peripheral chemoreceptors (carotid bodies) are the main sensing organs for hypoxaemia. During carotid surgery, the carotic body in the bifurcation of the common carotid artery is often involved and damaged or destroyed. Animals lose their ability to adapt to high altitude after experimental denervation of the carotid bodies. The objective of our study was to evaluate the ability of human patients to adapt to moderate altitude after single side carotid surgery. Blood gas analysis at rest at $171 \mathrm{~m}$ and after car and cable car transport to $1600 \mathrm{~m}$ before and after carotid surgery was performed. Mean(s.d.) $\mathrm{pa}_{2} \mathrm{O}_{2}$ decreased insignificantly from $74.8(3.56)$ at $171 \mathrm{~m}$ altitude to 71.6(2.07) at $1600 \mathrm{~m}(P=$ n.s. $)$, mean(s.d.) $\mathrm{pa}_{\mathrm{a}} \mathrm{CO}_{2}$ decreased significantly from $36.2(2.86)$ to $31.4(2.7) \mathrm{mmHg}(P<0.05)$ before carotid surgery. Months after surgery, a significant drop in $\mathrm{pa}_{2} \mathrm{O}_{2}$ occurred after identical passive exposure to moderate altitude: mean(s.d.) $\mathrm{Pa}_{2} \mathrm{CO}_{2}$ at $171 \mathrm{~m}$ $74.4(3.65) \mathrm{mmHg}$, at $1600 \mathrm{~m} 65.8(3.70) \mathrm{mmHg}(P<0.01)$, $\mathrm{pa}_{\mathrm{a}} \mathrm{CO}_{2}$ did not change significantly. Mean(s.d.) $\mathbf{p a}_{\mathrm{a}} \mathrm{CO}_{2}$ at $171 \mathrm{~m}: 36.0(2.35)$, at $1600 \mathrm{~m} 36.2(2.86) \mathrm{mmHg}(P=$ n.s. $)$. Although the sample investigated was small, after single side carotid surgery patients seem to lose their ability for satisfactory ventilatory response to acute exposure to moderate altitude. This is of possible alpine medical importance.
\end{abstract}

Keywords: carotid surgery, adaptation to moderate altitude

Not only the young and healthy use the mountains for leisure and sport, the group of aged mountaineers is growing. Even patients recovering from coronary bypass operations have taken part in trekking tours 1 . It is of growing importance to the sports medicine specialist to give adequate advice to patients with chronic diseases who want to take part in outdoor activities such as trekking, skiing or climbing.

Stenosis of the extracranial arteries is common in arteriosclerosis. Carotid endarterectomy is one of the main therapeutic measures in severe internal carotid stenosis. Surgeons usually pay no attention to the carotic body while performing this routine operation, indeed it is often not even mentioned in textbooks on surgical angiology ${ }^{2}$. The carotid body weighs about $10 \mathrm{mg}$ in man. It has a very rich blood flow for its

Address for correspondence: Dr G. Roeggla, Department of Emergency Medicine, University of Vienna, Waehringer Guertel 18-20, A-1090 Vienna, Austria mass and its oxygen consumption. It is, therefore, a very low extraction organ; that is, it extracts only a very small percentage of the oxygen in the blood presented to it. This explains how it is able to respond to arterial $\mathrm{p}_{\mathrm{a}} \mathrm{O}_{2}$ and not to oxygen content. Thus, it responds to hypoxaemia and not to anaemia or reduced flow. It is, therefore, the main organ for transduction of hypoxic signals in altitude and inducing hypoxic ventilatory response. In animal experiments, after removal or denervation of both carotid bodies, acute hypoxia actually causes depression of ventilation ${ }^{3}$. Up to now, no data have been reported on the altitude adaptation of patients after carotid surgery with possible involvement and damage of the carotic body.

The objective of our study was to evaluate the acute ventilatory adaptation in moderate altitude of patients after carotid surgery.

\section{Patients and methods}

This study was performed in the Austrian Alps at moderate altitude. Five patients participated after informed consent. Four male and one female patient, mean(s.d.) age 70(3.21) years at the time of operation, had elective carotid surgery because of severe symptomatic stenosis of the internal carotid. All five patients had a history of hypertension; no patient suffered from COPD or asthma; and all patients were ex-smokers for more than 2 years. No patient took part in a special training programme, all five estimated their physical fitness to be average, all were in a good state of health after the operation and able to go for walks on foot, and all were lowland dwellers. Before (interval 2 weeks - 2 months) and after (interval 6 months - 15 months) carotid surgery, capillary blood was obtained from the arterialized ear lobe of each patient ${ }^{4}$ at $171 \mathrm{~m}$ altitude. After passive transport by car to $1600 \mathrm{~m}$ and $45 \mathrm{~min}$ rest, the same procedure was repeated. Blood samples were stored in an ice water cooling box and analysed on a BGE Blood Gas Analyser (Instrumentation Laboratory, Milano, Italy) within $2 \mathrm{~h}$. Samples were taken between 0900 and 1100 at similar conditions, ambient temperature was constant at $21^{\circ} \mathrm{C}$ at $171 \mathrm{~m}$ (air conditioned university clinic) and $18^{\circ} \mathrm{C}$ at $1600 \mathrm{~m}$ (mountain restaurant). Breathing frequency and blood pressure were also recorded at each sampling. 
Table 1. Blood gas analysis $\mathrm{p}_{\mathrm{a}} \mathrm{O}_{2} / \mathrm{p}_{\mathrm{a}} \mathrm{CO}_{2}$ of five patients at $\mathrm{A}: 171 \mathrm{~m}$ altitude before surgery; $\mathrm{B}: 1600 \mathrm{~m}$ altitude before surgery; $\mathrm{C}: 171 \mathrm{~m}$ altitude after surgery; $\mathrm{D}: 1600 \mathrm{~m}$ altitude after surgery

\begin{tabular}{|c|c|c|c|c|c|c|c|c|}
\hline \multirow[t]{2}{*}{ Patient no. } & \multicolumn{2}{|c|}{$A$} & \multicolumn{2}{|c|}{ B } & \multicolumn{2}{|c|}{$C$} & \multicolumn{2}{|c|}{$D$} \\
\hline & $p_{\mathrm{a}} \mathrm{O}_{2}$ & $p_{\mathrm{a}} \mathrm{CO}_{2}$ & $p_{a} O_{2}$ & $p_{\mathrm{a}} \mathrm{CO}_{2}$ & $p_{a} O_{2}$ & $p_{a} C O_{2}$ & $p_{a} O_{2}$ & $p_{\mathrm{a}} \mathrm{CO}_{2}$ \\
\hline $\begin{array}{l}1 \\
2 \\
3 \\
4 \\
5 \\
\text { Mean(s.d.) }\end{array}$ & $\begin{array}{c}72 \\
80 \\
76 \\
71 \\
75 \\
74.8(3.6)\end{array}$ & $\begin{array}{c}36 \\
33 \\
34 \\
40 \\
38 \\
36.2(2.9)\end{array}$ & $\begin{array}{c}74 \\
72 \\
73 \\
69 \\
70 \\
71.6(2.1)\end{array}$ & $\begin{array}{c}33 \\
31 \\
27 \\
32 \\
34 \\
31.4(2.7)\end{array}$ & $\begin{array}{c}76 \\
74 \\
74 \\
79 \\
69 \\
74.4(3.7)\end{array}$ & $\begin{array}{c}34 \\
38 \\
38 \\
37 \\
33 \\
36.0(2.4)\end{array}$ & $\begin{array}{c}69 \\
70 \\
65 \\
64 \\
61 \\
65.8(3.7)\end{array}$ & $\begin{array}{c}38 \\
40 \\
33 \\
34 \\
36 \\
36.2(2.9)\end{array}$ \\
\hline
\end{tabular}

\section{Statistics}

After consideration of the essential test preconditions, the change in blood gas analysis, breathing frequency and blood pressure before and after transport up to moderate altitude were evaluated by paired $t$. test. The significance of the association between initial $\mathrm{p}_{\mathrm{a}} \mathrm{O}_{2}$ and $\mathrm{p}_{\mathrm{a}} \mathrm{O}_{2}$ at altitude was evaluated by linear regression and correlation. $P<0.05$ was considered significant.

\section{Results}

Before surgery, $\mathrm{p}_{a} \mathrm{O}_{2}$ was within the age-related norm in all patients 5 . After passive transport to $1600 \mathrm{~m}$, only a slight and insignificant decrease in $\mathrm{p}_{\mathrm{a}} \mathrm{O}_{2}$ was noted. Initial $\mathrm{p}_{\mathrm{a}} \mathrm{CO}_{2}$ decreased significantly after passive exposure to medium altitude. Months after stabilization from carotid surgery, $\mathrm{paO}_{2}$ at rest in the lowland was not changed. After transport to $1600 \mathrm{~m}$, a significant decrease of $\mathrm{p}_{\mathrm{a}} \mathrm{O}_{2}$ was noted. $\mathrm{P}_{\mathrm{a}} \mathrm{CO}_{2}$ on the contrary did not change significantly after postoperative altitude exposure (Table 1).

Blood gas analysis at lowland levels had no significant correlation to blood analysis at moderate altitude $\left(\mathrm{P}_{\mathrm{a}} \mathrm{O}_{2}(\mathrm{~A})\right.$ vs. $\mathrm{p}_{\mathrm{a}} \mathrm{O}_{2}(\mathrm{~B}): r=0.223, P=$ n.s.; $\mathrm{p}_{\mathrm{a}} \mathrm{CO}_{2}(\mathrm{~A})$ vs. $\mathrm{p}_{\mathrm{a}} \mathrm{CO}_{2}(\mathrm{~B}) r=0.569, P=$ n.s.; $\mathrm{p}_{\mathrm{a}} \mathrm{O}_{2}(\mathrm{C})$ vs. $\mathrm{paO}_{2}(\mathrm{D}): r=0.369, P=$ n.s.; $\mathrm{p}_{\mathrm{a}} \mathrm{CO}_{2}(\mathrm{C})$ vs. $\mathrm{p}_{\mathrm{a}} \mathrm{CO}_{2}(\mathrm{D}): r=0.149, P=$ n.s.). See Table 1 for abbreviations.

Mean(s.d.) breathing frequency was 14.4(1.5) initially and rose significantly to $16.0(1.8)$ after transport to moderate altitude $(P<0.01)$. After operation, breathing frequency was $15.2(1.1)$ at $171 \mathrm{~m}$ and $15.6(2.1)$ at $1600 \mathrm{~m}$ altitude, no significant change was recorded $(P=$ n.s. $)$. Mean(s.d.) blood pressure was initially $156(11 / 84)(11) \mathrm{mmHg}$ and did not change significantly.

\section{Discussion}

Most data produced in alpine medicine has dealt with healthy, often athletic, subjects at high altitude, although the greatest number of mountain tours are carried out at medium high altitude and the majority of mountaineers are not trained athletes, but go hiking as a leisure sport. More and more alpinists keep up these sports into their old age, and more and more alpinists suffer from chronic diseases, just like the rest of the population. The prevalence of the different forms of atherosclerosis in the aged alpinist are not known, interest has focused so far on coronary heart disease $\mathrm{e}^{1,6,7}$.

Atherosclerosis of the large extracranial vessels is not uncommon, and carotid endarterectomy is highly beneficial to certain patients with recent TIA or non-disabling strokes and ipsilateral high grade stenosis ${ }^{8}$. Surgeons usually pay no attention to the carotic body while performing carotid endarterectomy. In cats, the response to moderate hypoxia is biphasic: ventilation increases sharply for the first $5 \mathrm{~min}$ and then declines, but does not reach the initial values. Cats with denervated carotic bodies showed neither the initial increase nor the subsequent decrease in ventilation'. In this study, we evaluated the blood gas analysis after $45 \mathrm{~min}$ of rest at moderate altitude, so as not to measure while there might be an initial sharp increase of ventilation.

$\mathrm{P}_{\mathrm{a}} \mathrm{O}_{2}$ was initially the age-related norm in all five patients. No significant decrease in $\mathrm{p}_{\mathrm{a}} \mathrm{O}_{2}$ was noted after preoperative exposure at moderate altitude. The significant decrease in $\mathrm{p}_{\mathrm{a}} \mathrm{CO}_{2}$ indicates that the examined patients were not at their breathing limits and could compensate with prompt ventilatory response to moderate hypoxia. After carotid surgery, a significant drop of $\mathrm{paO}_{2}$ occurs in all patients at moderate altitude, the $\mathrm{paCO}_{2}$ values indicate no ventilatory response to altitude. A prediction of $\mathrm{p}_{\mathrm{a}} \mathrm{O}_{2}$ at altitude was not possible by the lowland values before and after surgery. Hypoxaemia was not severe, and no patient had any clinical signs of hypoxaemia. Breathing frequency increased after transport to moderate altitude before operation, and no change in breathing frequency at lowland levels and at $1600 \mathrm{~m}$ was recorded after operation.

Carotid surgery was performed on one side only in all patients. The absence of adequate respiratory response to moderate hypoxia was, therefore, surprising. The chemoreceptors in the aorta are of no importance in respiratory regulation in $\operatorname{man}^{10}$. No research is known to evaluate possible dysfunction of the carotic bodies in atherosclerotic carotids. We cannot provide a satisfactory explanation for the reported intolerance to moderate hypoxia in this study, possibly the haemodynamic situation after surgery improved in comparison to the contralateral side to surgery.

In conclusion, although the investigated sample was small, we presume that certain patients lose their ability for satisfactory ventilatory response to moder- 
ate altitude hypoxia even after single side carotid surgery. Until further studies provide enough information to predict $\mathrm{p}_{\mathrm{a}} \mathrm{O}_{2}$ at altitude after carotid surgery, caution in the exposure to altitude of all patients recovering from carotic surgery is necessary. This is of potential alpine medical and aeromedical importance.

\section{References}

1 Drummond R. Will mountain trekkers have heart attacks? JAMA 1989; 261: 1045-6.

2 Kappert A. Angiology: surgical therapy. Bern, Switzerland: Hans Huber Verlag, 1976.

3 Ward MP, Milledge JS, West JB. High altitude medicine and physiology. London, UK: Chapman and Hall. 1989.
4 Haber P, Harnoncourt K, Forche G. Die österreichische Standardisierung der Blutgasanalyse. Österr Ärztezeitung 1988; 43: 32 and 53-8.

5 Ulmer WT, Reichel G, Nolte D. Lungenfunktion. Stuttgart, Germany: Thieme, 1976.

6 Froelicher VF, West GB. Trekking in Nepal: safety after coronary artery bypass. JAMA 1988; 260: 2219-9.

7 Morris CK, Froelicher VF. Cardiovascular screening for high altitude trekking. Clin J Sport Med 1991; 1: 100-3.

8 North American Symptomatic Carotid Endarterectomy Trial Collaborators. Beneficial effect of carotid endarterectomy in symptomatic patients with high grade carotid stenosis. N Engl J Med 1991; 325: 445-53.

9 Long WQ Giesbrecht GG, Anthonisen NR. Ventilatory response to moderate hypoxia in awake chemodenerved cats. J Appl Physiol 1993; 74: 805-10.

10 Buehlmann AA. Lunge und Atmung. In: Siegentaler, E, ed. Klinische Pathophysiologie. Stuttgart, Germany: Thieme Verlag, 1987. 